\title{
Identification of Stress-Slip LaW for Bar or Fiber Pullout by Size EFFECT TeSTS
}

\author{
By Zdeněk P. Bažant, ${ }^{1}$ Fellow, ASCE, Zhengzhi $\mathrm{Li}^{2}{ }^{2}$ and Michael Thoma ${ }^{3}$
}

\begin{abstract}
AвstRact: Test results on the size effect in the pullout strength of reinforcing bars embedded in concrete are presented. Attention is focused on failures due solely to interface slip, with no cracking in the surrounding concrete. This type of failure is achieved by using smooth round bars and a sufficiently large ratio of bar diameter to embedment length. Elimination of cracking in the surrounding concrete makes it possible to study the characteristics of the interfacial shear fracture between steel and concrete. The results of tests of geometrically similar specimens show that interfacial shear fracture causes a size effect on the nominal strength in pullout. The size effect is found to be transitional between plastic failure (the current approach of concrete design codes, for which there is no size effect) and linear elastic fracture mechanics (for which the size effect is the maximum possible). This transitional size effect can be approximately described by the size effect law proposed by Bažant in 1984 for quasibrittle failures in general. By fitting a theoretical formula obtained in a previous study (by Bažant and Desmorat in 1994) to the size effect data, the basic characteristics of the stressslip law for interface fracture are determined. These include the interfacial fracture energy, the shear bond strength (debonding shear stress), and the residual frictional shear stress. The same method could be used for identifying the interfacial fracture characteristics of other materials, e.g., fibers in cementitious composites.
\end{abstract}

\section{INTRODUCTION}

The problem of pullout of reinforcing bars from concrete or fibers from the matrix of a composite material has been studied intensely and many significant results have already been obtained. Two concepts have been used as the criterion of pullout failure: (1) The interface shear strength criterion (Lawrence 1972; Takaru and Arridge 1973; Yue and Cheung 1992; Hsueh 1990, 1991); and (2) fracture mechanics criterion of critical energy release rate (Guerney and Hunt 1967; Outwater and Murphy 1969; Stang and Shah 1986), which was combined with the consideration of friction between the debonded fiber and the matrix in some works (Gao et al. 1988; Hutchinson and Jensen 1990).

More realistic is a generalized fracture mechanics approach that combines both concepts. It is based on the relation of the interfacial shear stress $\tau_{s}$ (bond stress) to the interfacial slip; in short, the stress-slip law. This law involves the strength limit as well as the fracture energy. It may involve a rising linear part simulating the elastic shear deformation of a thin layer of matrix adjacent to the interface.

The stress-slip law is characterized by postpeak softening, which is sometimes considered as a sudden stress drop, but is more realistically modeled as a progressive softening. Because of the softening, the interfacial slip represents shear fracture. Normally the stress-slip law possesses residual shear strength $\tau_{f}$, which can be regarded as friction (more precisely, the dynamic friction). From the fracture mechanics viewpoint, the area under the stress-slip curve and above the friction limit represents the shear fracture energy of the interface $G_{f}$, which is a basic interface property. The values of the shear strength, fracture energy, and frictional stress can in general depend on the confining pressure from the surrounding matrix (the normal stress across the interface).

\footnotetext{
'Walter P. Murphy Prof. of Civ. Engrg. and Mat. Sci., Northwestern Univ., Evanston, IL 60208.

'Grad. Res. Asst., Dept. of Civ. Engrg., Northwestern Univ., Evanston, IL.

${ }^{3}$ Visiting Res. Asst., Dept. of Civ. Engrg., Northwestern Univ., Evanston, IL.

Note. Associate Editor: Jean-Lou A. Chameau. Discussion open until Octoher 1, 1995. To extend the closing date one month, a written request must be filed with the ASCE Manager of Journals. The manuscript for this paper was submitted for review and possible publication on March 11. 1994. This paper is part of the Journal of Engineering Mechanics, Vol. 121, No. 5. May, 1995. OASCE, ISSN 0733-9399/95/(0015-(0620$0625 / \$ 2.00+\$ .25$ per page. Paper No. 8073
}

Although the stress-slip law for the interface is a basic characteristic of composite materials, it is difficult to measure directly. Some success in this regard has nevertheless been achieved [e.g., Edwards and Yannopoulos (1979), Dörr (1978), Nilson (1972), Lahnert et al. (1984), Giuriani et al. (1991), Rots (1985)]. It is more effective to deduce the stress-slip law indirectly from some other types of observations or analytical considerations [e.g., Naaman (1991); Alwan et al. (1991); and other works cited in Bažant and Desmorat (1994)]. In a study by Bažant and Desmorat (1994), it was shown that the stress-slip law can be identified from measurements of the size effect on the pullout strength when geometrically similar specimens of different sizes are tested. A simplified method of identification was proposed and illustrated by a numerical example, but practical application has not been given because of lack of test data. The objective of this paper is to report test results of size effect on pullout, and to identify the stressslip law for the steel-concrete interface from these results.

The identification problem requires a sufficiently simple solution, which is preferably in a closed and invertible form. Such a simple solution was obtained in a study by Bažant and Desmorat (1994), in which the pullout problem was simplified as one-dimensional, with the matrix represented as an elastic bar or hollow cylinder surrounding the pulled bar or fiber. Although the one-dimensional simplification is no doubt too crude for some purposes, it is no worse than the assumption of an elastic Winkler foundation as a replacement for an elastic half-space. Of course, the equivalent elastic stiffness of the surrounding hollow cylinder that models the matrix must be properly determined, either by a more sophisticated analysis or by tests.

It is now well understood that softening material properties always engender size effect. Normally the size effect in pullout failures arises from two sources: (1) The fracturing of the matrix surrounding the bar or fiber; and (2) the softening in the stress-slip law, as already described. Obviously, to determine the stress-slip law, one must conceive a special type of pullout test in which there is no fracturing in the matrix, only the slip in the interface. This is the basic idea of the experiments reported here. As will be seen, the pullout failure of reinforcing bars due exclusively to the interface slip can be obtained if a smooth round bar (with no lugs) is used and if the embedment length of the bar or fiber is sufficiently short.

The pullout failures of reinforcing bars in concrete or fibers 
in composites exhibit some different characteristics. However, these differences are mainly due to the fracturing of the matrix surrounding the bar or fiber (for example the fracture induced by lugs on the reinforcing bars in concrete). These differences are probably small if the failure is due to the interfacial slip alone, which is the case here. Anyway, because the pullout problem is simplified as one-dimensional, it is impossible to make a distinction between fibers and bars (except in terms of the effective values of material interface parameters).

It has been widely believed that size effects in structures are caused by the randomness of material strength, as described by the Weibull-type theory. However, this is true only when the structure fails at the initiation of material failure (or fracture). In structures that fail only after large softening zones have developed, the statistical size effect is minor and is completely overshadowed by the size effect resulting from stress redistribution before failure (Bažant and Xi 1991).

\section{TEST OF PULLOUT DUE TO INTERFACIAL SLIP ALONE}

The specimens tested, shown in Fig. 1, were concrete cubes of sides $L=1.5$ in., 3 in., 6 in., and 12 in. (38.1, 76.2, 154.4, and $304.8 \mathrm{~mm}$ ), in which steel bars of diameters $D=0.125$ in., 0.25 in., 0.5 in., and 1 in. $(3.2,6.4,12.8$, and $25.4 \mathrm{~mm})$ were embedded. In this manner, the perfect geometric similarity of specimens of different sizes was preserved. Three specimens of each size were tested in most cases. The bars were smooth to ensure that the pullout failure be caused solely by interfacial slip, with no fracturing in the surrounding concrete. This mode of failure was borne out by the tests. The round smooth rods were slightly rusty at the time of casting; however, this condition is not undesirable since some rusting

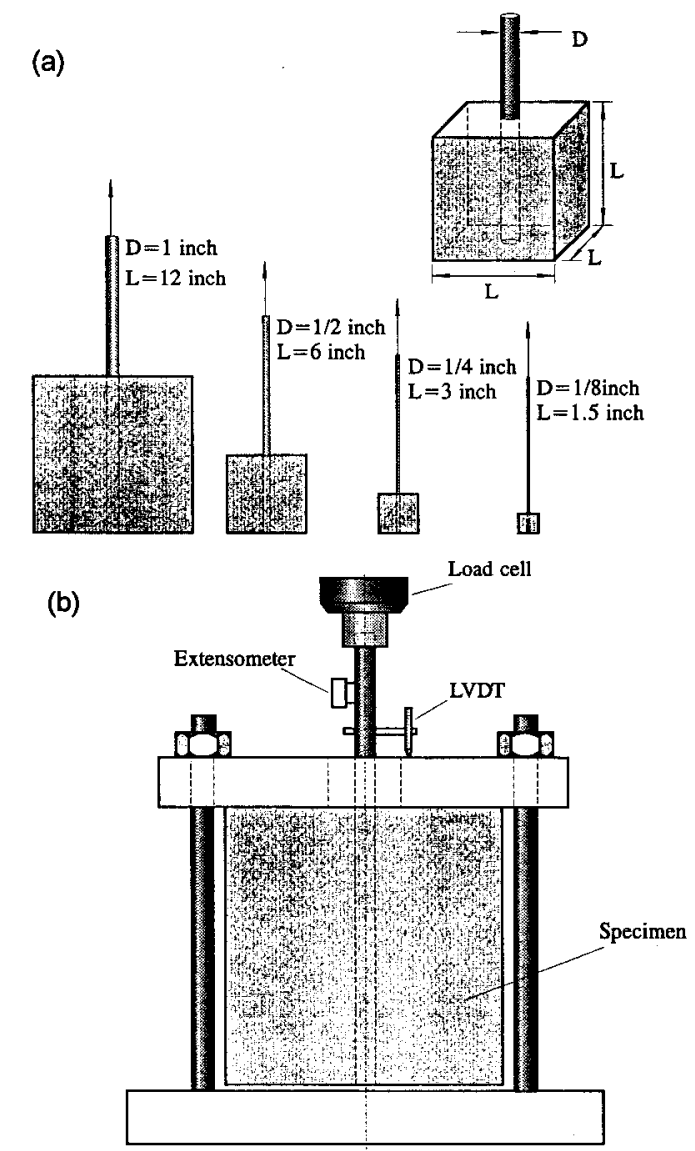

FIG. 1. (a) Geometry of Pullout Test Specimens; (b) Loading Frame and Test Arrangement is normally present in practice. Based on the expected average bond strength (Naaman and Najm 1991), the bar size was chosen so that yielding of the steel could not occur before the pullout failure of the interface, and this was also borne out by the tests. The part of the steel bars sticking out of the concrete cube was $10 \mathrm{in}$. (254 $\mathrm{mm})$ long for each size.

The cubes were made of concrete of standard cylindrical strength $f_{c}^{\prime}=7,290 \mathrm{psi}(50.26 \mathrm{MPa})$ for normally cured specimens, and $f_{c}^{\prime}=5,220 \mathrm{psi}(36.0 \mathrm{MPa})$ for the concrete cured in an accelerated manner [tested on cylinders of diameter 3 in. $(76.2 \mathrm{~mm})$, at the time of the tests]. Young's elastic modulus of concrete was determined as the mean initial stressstrain slope from a set of standard cylindrical compression tests for the same batch of concrete; for normal curing it was $4.31 \times 10^{6} \mathrm{psi}(29.7 \mathrm{GPa})$, and for accelerated curing it was $4.47 \times 10^{6} \mathrm{psi}(30.8 \mathrm{GPa})$. Young's modulus of the steel bars was $30.5 \times 10^{6} \mathrm{psi}(210.0 \mathrm{GPa})$. For both sets, the companion cylinders for the tests of strength had the same curing history. In the concrete mix, the ratio water:cement:sand:gravel was $0.6: 1: 2: 2$, by weight. The aggregate consisted of granite, quartz, etc., gravel and quartz sand of maximum grain sizes $3 / 8$ in. $(9.6 \mathrm{~mm})$ and $0.132 \mathrm{in} .(3.35 \mathrm{~mm})$, respectively. Both were washed and air-dried for $40 \mathrm{hr}$ or $48 \mathrm{hr}$ prior to mixing. Portland cement of ASTM type I, without any admixtures, was used. Two sets of specimens of all sizes, each from one batch of concrete, were cast in wooden molds [Fig.1(a)]. The steel bars were vertical during casting. The specimens were unmolded one day after casting. The first set of specimens was stored in a fog room at nearly $100 \%$ relative humidity and $20^{\circ} \mathrm{C}$ temperature for 28 days, and then tested. The second set of specimens was cured in water for 7 days at $50^{\circ} \mathrm{C}$, to achieve accelerated curing. In the second set of specimens cured in water, the largest cube, with a 12 in. side, was omitted because of the limited size of the heated chamber. In spite of the lower strength of specimens cured in the accelerated manner, the bond strength was about the same as that for specimens cured in the standard manner.

The specimens were tested immediately after the curing. So the specimen bulk was still wet during the test, which means that microcracking due to drying could not have occurred in the specimens. All the specimens were tested in a $20 \mathrm{kip}(89.0 \mathrm{kN})$ closed-loop controlled MTS testing machine. All the tests were displacement-controlled. The displacement rate was kept constant during each test and was chosen so that the maximum load for specimens of all sizes would occur in about $10 \mathrm{~min}$ [for the 6-in. cubes (Fig. 2) the displacement rate was $0.003 \mathrm{in} . / \mathrm{min}$ or $0.076 \mathrm{~mm} / \mathrm{min}$; for the 12 -in. cubes it was slightly higher, and for the 1.5 -in. cubes it was slightly smaller]. The strain of the steel bar outside the cube was recorded by a MTS extensometer. The displacement was measured on the steel bar as close to the face of the cube as possible; that is, right above the steel plate providing the reaction [Fig. 1(b)].

\section{TEST RESULTS AND SIZE EFFECT OBSERVED}

The specimens of both series failed by pure interfacial slip, in contrast to the earlier pullout tests conducted by Bažant and Sener (1988). No visible cracking occurred in the concrete cubes; this means that the objective of avoiding the fracturing of concrete around the bars has been achieved, and the observed postpeak softening and size effect must be attributed strictly to the interface fracture. Some typical load-deflection diagrams are shown in Fig. 3 (the initial increase of the slope is due to the gradual seating of the reaction plate). As seen in Fig. 3, the larger the specimen, the steeper the postpeak descent. This property is characteristic of all structures undergoing damage localization.

The test results for standard and accelerated curing are 


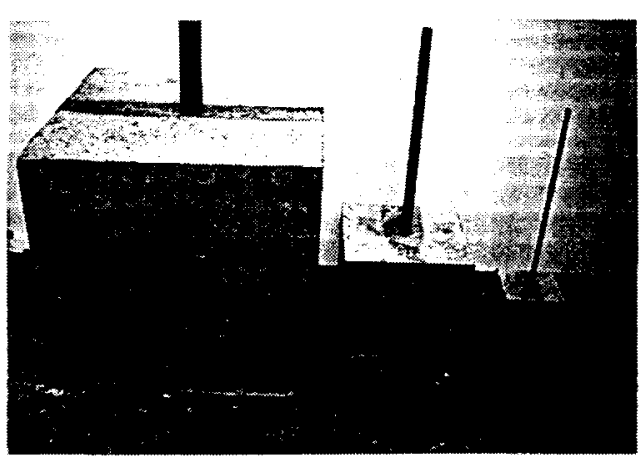

(a)

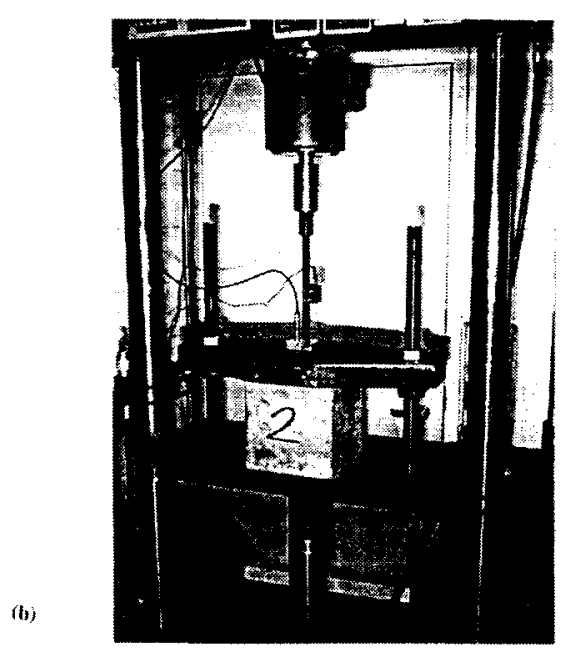

FIG. 2. Set of Test Specimens of Various Sizes (before Testing) and of Test Setup for 6-in. Specimen
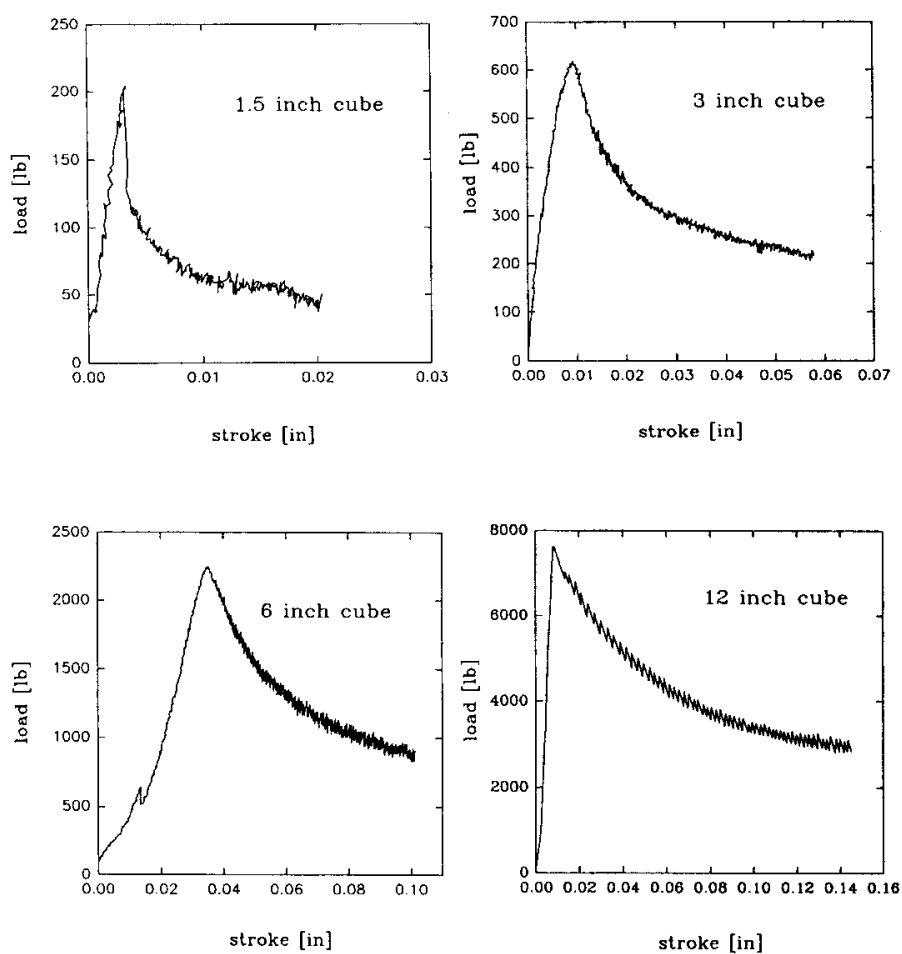

FIG. 3. Typical Load-Slip Diagrams for Specimens of Various Sizes (for Standard Curing and Accelerated Curing)
TABLE 1. Test Results for Standard and Accelerated Curing Specimens

\begin{tabular}{|c|c|c|c|c|c|c|c|}
\hline \multicolumn{4}{|c|}{ Standard Curing } & \multicolumn{4}{|c|}{ Accelerated Curing } \\
\hline $\begin{array}{c}\text { Diameter } \\
D \\
\text { (in.) } \\
\text { (1) }\end{array}$ & $\begin{array}{l}\text { Cube } \\
\text { side } \\
\text { (in.) } \\
\text { (2) }\end{array}$ & $\begin{array}{c}\text { Maximum } \\
\text { load } \\
\text { (lb) } \\
\text { (3) }\end{array}$ & $\begin{array}{c}\sigma_{d m} \\
(p s i) \\
(4)\end{array}$ & $\begin{array}{c}\text { Diameter } \\
D \\
\text { (in.) } \\
\text { (5) }\end{array}$ & $\begin{array}{l}\text { Cube } \\
\text { side } \\
\text { (in.) } \\
\text { (6) }\end{array}$ & $\begin{array}{c}\text { Maximum } \\
\text { load } \\
\text { (lb) } \\
\text { (7) }\end{array}$ & $\begin{array}{c}\sigma_{d m} \\
(p s i) \\
(8)\end{array}$ \\
\hline $1 / 8$ & 1.5 & 253 & 16,297 & $1 / 8$ & 1.5 & 230 & 18,742 \\
\hline $1 / 8$ & 1.5 & 171 & 18,229 & $1 / 8$ & 1.5 & 175 & 14,260 \\
\hline $1 / 8$ & 1.5 & 224 & 13,957 & $1 / 8$ & 1.5 & 201 & 16,379 \\
\hline $1 / 8$ & 1.5 & 200 & 20,616 & $1 / 4$ & 3 & 613 & 12,488 \\
\hline $1 / 4$ & 3 & 561 & 11,429 & $1 / 4$ & 3 & 588 & 11,979 \\
\hline $1 / 2$ & 6 & 3,605 & 18,360 & $1 / 4$ & 3 & 859 & 17,499 \\
\hline $1 / 2$ & 6 & 3,500 & 17,825 & $1 / 4$ & 3 & 763 & 15,544 \\
\hline $1 / 2$ & 6 & 2,700 & 13,751 & $1 / 2$ & 6 & 1,781 & 9,070 \\
\hline 1 & 12 & 10,300 & 13,114 & $1 / 2$ & 6 & 3,750 & 19,098 \\
\hline 1 & 12 & 8,009 & 10,117 & $1 / 2$ & 6 & 2,249 & 11,454 \\
\hline 1 & 12 & 7,754 & 9,872 & $1 / 2$ & 6 & 3,247 & 16,537 \\
\hline
\end{tabular}

shown in Table 1. The intention was to test four specimens for each size in each set; however, a few tests did not work out.

Dividing the maximum load by the embedded steel surface area, one obtains the average shear bond strength, which is taken as $\tau_{d}$. Its value for these tests ranged from 189 psi to 429 psi $(1.30-2.96 \mathrm{MPa})$, for both sets of specimens. This value is similar to the values obtained by Naman and Najm (1991). This value is considerably smaller than the values predicted by the formulas of Orangun et al. (1977) or by the American Concrete Institute (ACI) ("Building" 1983). However, these formulas are not intended for smooth bars, but for deformed bars whose failure causes severe cracking of concrete.

Because the load-deflection diagram exhibits postpeak softening, which is not caused by geometrically nonlinear effects of buckling, one must expect a size effect that is approximately described by the size effect law (Bažant 1984; Bažant et al. 1991):

$$
\sigma_{N}-\sigma_{0}=B f_{i}^{\prime}(1+\beta)^{-1 / 2}
$$

in which $\sigma_{N}=$ nominal strength of the bar-matrix system, defined as $4 P_{\max } / \pi D^{2}$ where $P_{\max }=$ maximum load in the test; $\beta=D / D_{0}=$ relative size, $D=$ characteristic size taken as the bar diameter, $\sigma_{0}=$ residual (frictional) nominal strength; $f_{t}^{\prime}=$ direct tensile strength of concrete (introduced solely for convenience); and $B, D_{0}=$ two constants to be determined by the regression of test data. The direct tensile strength was estimated from the ACI formula ("Building" 1983), $f_{1}^{\prime}=$ $6 \sqrt{f_{c}^{\prime}}$ (where both $f_{c}^{\prime}$ and $f_{\prime}^{\prime}$, are in psi). The residual frictional strength is determined from the final plateau of the loaddisplacement diagram, as the final load value divided by the cross-section area of the steel bar. From the present tests, $\sigma_{i}$ $=3,310 \mathrm{psi}(22.8 \mathrm{MPa})$ for standard curing and $\sigma_{0}=4,180$ psi (28.8 MPa) for accelerated curing.

As shown earlier (RILEM 1990), (1) can be converted to a linear regression plot

$$
Y=A X+C \text { with } Y=f_{!}^{\prime 2}\left(\sigma_{N}-\sigma_{0}\right)^{2}, \quad X=D
$$

The measured data are shown as the circled points in the plot $Y$ versus $X$, in Fig. 4(a), for the set of specimens cured in the standard manner and, in Fig. 4(b), for the set of specimens cured in an accelerated manner. The regression lines $Y=$ $A X+C$ are also shown in these plots. The constants of the size effect law (1) can than be obtained as $B=C^{-1 / 2}$ and $D_{0}$ $=C / A$, in which $A$ is the slope of the regression line and $C$ is the vertical intercept. In this manner, it is found that $B=$ $2.18 \mathrm{in}$. and $D_{0}=0.297 \mathrm{in}$. $(7.54 \mathrm{~mm})$ in the case of standard curing, and $B=3.05$ in. and $D_{0}=0.198$ in. $(5.03 \mathrm{~mm})$ in 

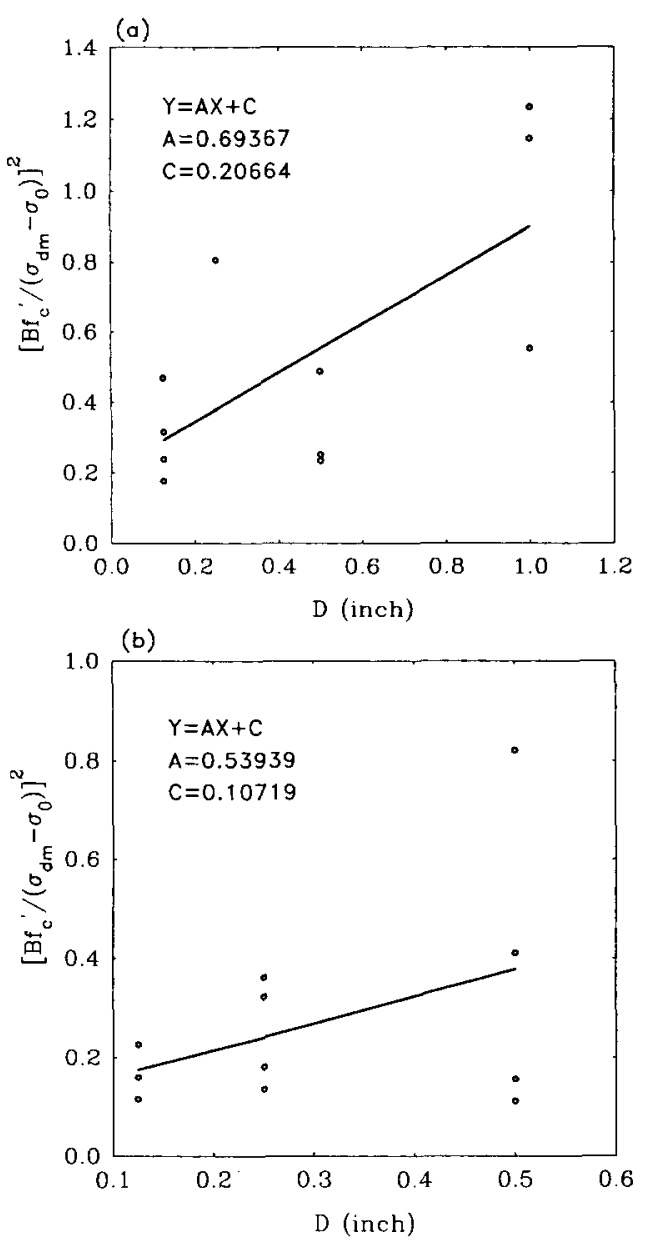

FIG. 4. Linear Regressions of Test Data according to Size Effect Law: (a) Standard Curing; (b) Accelerated Curing

the case of accelerated curing. The size effect plots corresponding to these parameters are shown as the curves in Figs. $5(a$ and $b)$. The curve of the size effect represents a gradual transition from a horizontal asymptote representing the strength criterion to an asymptote of slope -0.5 , representing the size effect of linear elastic fracture mechanics.

The scatter or the test data in Figs. 4 and 5 is quite large. However, large scatter has generally been typical of bond strength measurements in the past. In spite of the large scatter, it is clear that a size effect is present and that the mean slope of the size effect plot in Fig. 5 is intermediate between the strength criterion and the linear elastic fracture mechanics, as expected. It cannot be claimed that the test results validate the use of the size effect law; however, they are not in disagreement with this law.

\section{IDENTIFICATION OF INTERFACE CHARACTERISTICS FROM SIZE EFFECT}

In an earlier study, Bažant and Desmorat (1994), assumed that the stress-slip law, that is, the relationship of the shear (bond) stress $\tau$ at the interface to the relative slip $v$ at the interface, has the form shown in Fig. 6. The softening is considered to be linear, starting from the shear bond strength $\tau_{d}$, and there is a terminal shear stress $\tau_{f}$, representing friction. The area under the softening diagram above the frictional plateau (cross-hatched in Fig. 6) represents the interfacial fracture energy $G_{f}$ per unit area of the interface. Its value determines the softening slope in Fig. 1(a).

In the preceding analysis, the interaction between the reinforcing bar (or fiber) and the surrounding matrix was sim- (a)
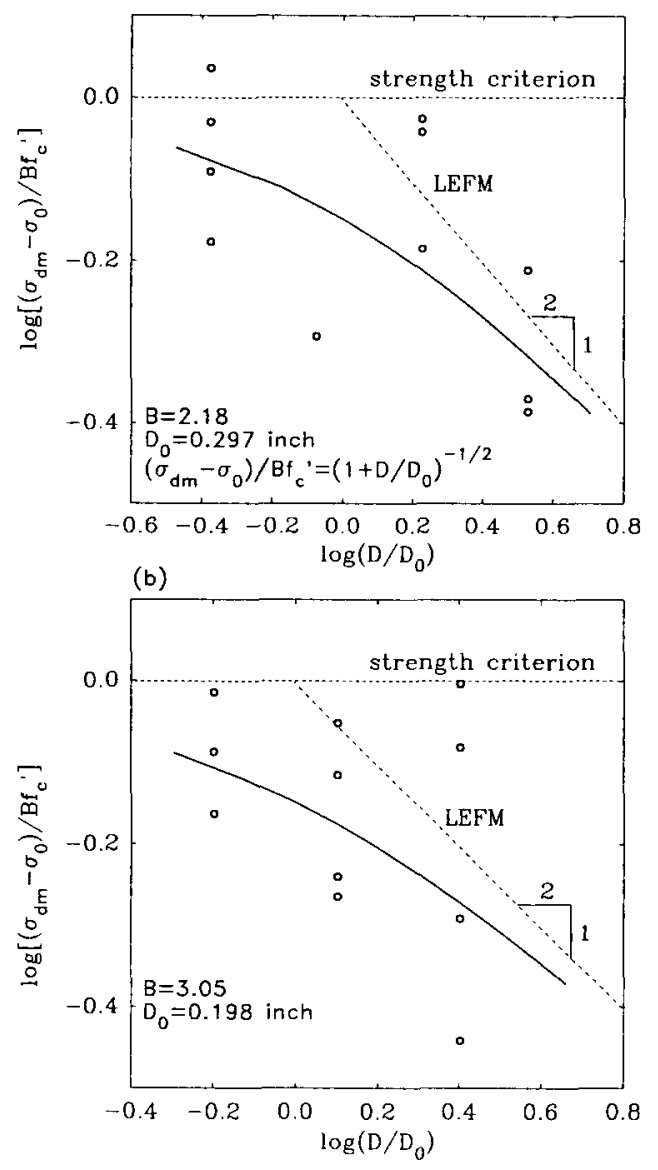

FIG. 5. Size Effect Plots of Test Results in Double Logarithmic Scales and Their Optimum Fit by Size Effect Law: (a) Standard Curing; (b) Accelerated Curing

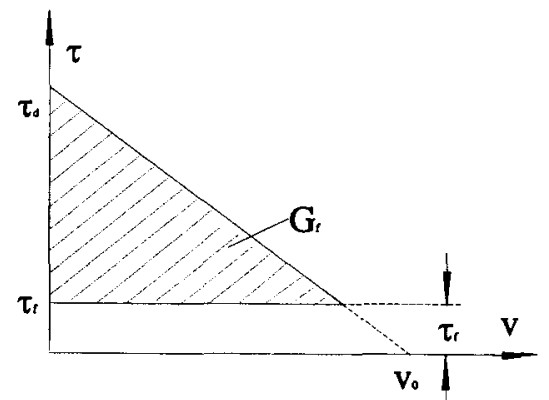

FIG. 6. Stress-Slip Law for Steel-Concrete Interface

plified as a one-dimensional problem. This means that the concrete surrounding the steel bar is treated as a bar (hollow cylinder) in which the cross sections remain plain. Under this simplification, it was possible to obtain for the size effect an analytical solution that was simple enough to identify the interface material characteristics $\tau_{d}, \tau_{f}$, and $G_{f}$. It was possible to solve these characteristics explicitly in terms of the parameters of the size effect law (1).

Two cases had to be distinguished in the aforementioned solution: (1) The interface slip cracks join before $\tau_{f}$ is reached [Fig. 7(a)]; and (2) $\tau_{f}$ is reached before the cracks join [Fig. 7(b)]. The following equations have been obtained for these two cases:

$$
\sigma_{d i ! n}^{\prime}=\frac{8 \tau_{d \prime}}{\omega D} \sin \frac{\omega L}{2} \text { for } \omega L \leq 2 \arccos \frac{\tau_{f}}{\tau_{d \prime}}
$$



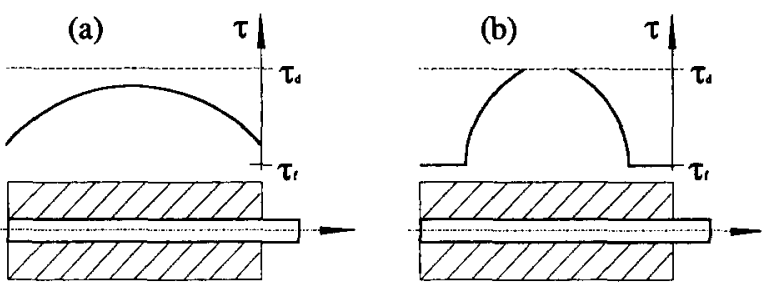

FIG. 7. Two Types of Interface Shear Stress Distribution at Maximum Load

TABLE 2. Fracture Characteristics Identified from Tests

\begin{tabular}{c|c|c}
\hline \hline $\begin{array}{c}\text { Material } \\
\text { parameter } \\
(1)\end{array}$ & $\begin{array}{c}\text { 28-Day standard curing } \\
(2)\end{array}$ & $\begin{array}{c}\text { Accelerated curing } \\
(3)\end{array}$ \\
\hline \hline$\tau_{\prime}$ & $68.9 \mathrm{psi}(0.47 \mathrm{MPa})$ & $87.1 \mathrm{psi}(0.59 \mathrm{MPa})$ \\
$\tau_{\tau^{\prime}}$ & $400.3 \mathrm{psi}(2.76 \mathrm{MPa})$ & $333.3 \mathrm{psi}(2.29 \mathrm{MPa})$ \\
$v_{1 \prime}$ & $5.8 \times 10^{-3} \mathrm{in}$. & $6.4 \times 10^{-3} \mathrm{in.}$ \\
$\left(148 \times 10^{-3} \mathrm{~mm}\right)$ & $\left(162 \times 10^{-3} \mathrm{~mm}\right)$ \\
$G_{i}$ & $140 \mathrm{~J} / \mathrm{m}^{2}$ & $102 \mathrm{~J} / \mathrm{m}^{2}$ \\
\hline \hline
\end{tabular}

$$
\sigma_{d ! m}^{\prime \prime}=\frac{8 \tau_{d}}{\omega D} \sqrt{1-\frac{\tau_{f}^{2}}{\tau_{d}^{2}}}+\frac{4 \tau_{l}}{\omega D}\left(\omega L-2 \arccos \frac{\tau_{f}}{\tau_{d}}\right)
$$

$$
\text { for } \omega L>2 \arccos \frac{\tau_{f}}{\tau_{d}}
$$

The superscripts $I$ and $I I$ label the first and second cases; $\sigma_{d m}$ $=$ maximum axial stress in the bar; $\omega^{2}=4(1+\phi) \tau_{d} / E_{f} v_{0} D$ with $\phi=A_{f} E_{f} / A_{m} E_{m}$, where $A_{f}=\pi D^{2} / 4, A_{m}=\pi\left(d^{2}-\right.$ $\left.D^{2}\right) / 4 ; v_{0}=$ critical slip shown in Fig. $6 ; D=$ reinforcing bar diameter; and $d=$ outer diameter of the effective crosssection area of the concrete (matrix) surrounding the steel bar.

When geometrically similar specimens are considered, $L / D$ and $d / D$ are constants. From (3) and (4) one can plot the size effect curve of $\log \sigma_{d m}$ versus $\log D$. This curve has the same asymptotes as the size effect law (1) plotted in (4). By matching these asymptotes to the horizontal and inclined asymptotes of the size effect law (1), it has been shown that

$$
\begin{gathered}
\tau_{d}=\frac{D}{4 L} B f_{c}^{\prime}+\tau_{f} \\
v_{1 \prime}=\frac{1+\phi}{2} \frac{\left(B f_{c}^{\prime}\right)^{2}}{\tau_{d} E_{f}} D_{0}\left(\sqrt{1-\frac{\tau_{f}^{2}}{\tau_{d}^{2}}}-\frac{\tau_{f}}{\tau_{d}} \arccos \frac{\tau_{f}}{\tau_{d}}\right)^{2}
\end{gathered}
$$

These equations make it possible to determine the values of the interface fracture characteristics. However, before these equations are evaluated, one must determine the residual frictional shear stress, which is simply given by

$$
\tau_{f}=\frac{D}{4 L} \sigma_{0}=\frac{\sigma_{0}}{48}
$$

The interfacial fracture energy can then be calculated as

$$
G_{i}=\frac{v_{t 1}}{2} \tau_{d}\left(1-\frac{\tau_{f}}{\tau_{d}}\right)^{2}
$$

Eqs. (6)-(8) have been applied to the size effect parameters obtained from the present test results. The resulting values of the interface fracture characteristics for specimens cured in the standard manner and in the accelerated manner are listed in Table 2 . The values of the debonding stress $\tau_{d}$ (interface shear strength) and the residual frictional shear stress $\tau_{f}$ are also given; they are similar for both methods of curing, however, the interfacial fracture energies are quite different and the postpeak softening is steeper for the accelerated curing tests. Using the equations given by Bažant and Desmorat (1994), one can also determine the length of the interfacial fracture process zone. The interface fracture energies obtained are about $80 \%$ and $60 \%$ of the fracture energy of concrete (assumed to be $150-200 \mathrm{~J} / \mathrm{m}^{2}$ )

The present test data, however, are too limited and their scatter is too high for determining the precise shape of the stress-slip law for the steel-concrete interface. The softening curve of the stress-slip law may of course be a smooth curve and may be more complicated than the curve in Fig. 6. The characteristics of the stress-slip law in Fig. 6, which have been identified from the test data, should be regarded as merely approximate.

\section{CONCLUSIONS}

1. Slip and shear fracture at the steel-concrete interface engender a size effect on the nominal strength of barmatrix system, even if no fracture takes place in concrete. This implies that the interfacial stress-slip curve must exhibit postpeak softening.

2. The size effect caused by interface slip is transitional between the plastic limit analysis and linear elastic fracture mechanics, and is not in disagreement with the general size effect law proposed by Bažant (1984), based on the energy release analysis with a dimensional analysis and similitude arguments.

3. The interface fracture characteristics, including the interface fracture energy, interface shear bond strength, and a residual frictional strength, can be identified from the results of tests of the size effect on bar pullout from geometrically similar specimens of different sizes.

4. To be able to identify the interfacial shear fracture characteristics from the size effect tests, it is necessary to design the tests in such a manner that the failure is due exclusively to interfacial slip, with no cracking in the surrounding concrete. In the case of reinforced concrete, this can be achieved by using smooth round bars (with no lugs) that have a sufficiently large ratio of bar diameter to embedment length.

\section{ACKNOWLEDGMENT}

Partial financial support under the Air Force Office of Scientific Research (AFOSR) grant 91-0140 to Northwestern University is gratefully acknowledged. Further support for the conduct of experiments was also obtained from the Center of Advanced Cement-Based Materials at Northwestern University.

\section{APPENDIX. REFERENCES}

Alwan, J. M., Naaman, A. E., and Hansen, W. (1991). "Pull-out work of steel fibers from cementitious composites: analytical investigation." Cement and Concrete Composites, 13(4), 247-255.

Bažant, Z. P. (1984). "Size effect in blunt fracture: concrete, rock. metal." J. Engrg. Mech. ASCE, 110(4), 518-535.

Bažant, Z. P., and Sener, S. (1988). "Size effect in pullout tests." $A C I$ Mat. J., Vol. 85, 347-351.

Bažant, Z. P., Xi, Y., and Reid, S. G. (1991a). "Statistical size effect in quasi-brittle structures. I: Is Weibull theory applicable?"J. Engrg. Mech. ASCE, 117(11), 2609-2622

Bažant, Z. P and Xi. Y. (1991). "Statistical size effect in quasi-brittle structures. II. Nonlocal theory." J. Engrg. Mech., ASCE, 117(11), $2623-2640$

Bažant, Z. P., and Cedolin. L. (1991). Stability of structures: elastic, inelastic, fracture and damage theories. Oxford University Press. $\mathrm{New}$ York, N.Y.

Bažant, Z. P., and Desmorat. R. (1994). "Size effect in fiber or bar pullout with interface fracture and softening slip." J. Engrg. Mech. ASCE, 120(9), 1945-1962. 
"Building code requirements for reinforced concrete." (1983). Am. Concrete Inst. (ACI) Committee 318, Detroit, Mich.

Dörr, K. (1978). "Bond-bchaviour of ribbed reinforcements under transversal pressure." Proc., Symp. on Nonlinear Behaviour of R. C. Spatial Structures, Int. Association for Shell and Spatial Struct., Darmstadt, Germany, 13-24.

Edwards, A. D.. and Yannopoulos, P. J. (1979). "Local bond-stress to slip relationship for hot rolled deformed bars and mild steel plain bars." $A C I J, 76(3), 405-420$.

Gao, Y.-C. Mai, Y.-W., and Cotterell, B. (1988). "Fracture of fiberreinforced materials." J. Appl. Mathematics and Phys., Vol. 39, 550572.

Giuriani. E., Plizzari, G., and Schumm, C. (1991). "Role of stirrups and residual tensile strength of cracked concrete on bond." J. Struct. Engrg., ASCE, 117(1), 1-18

Guerney, C., and Hunt, J. (196i). "Quasi-static crack propagation." Proc, Royal Soc. of London, London, England, Ser. A, Vol. 229, $508-524$.

Hsuch. C.-H. (1990a). "Interfacial debonding and fiber pullout stresses of fiber reinforced composites. II: nonconstant interfacial bond strength." Mat. Sci. and Engrg., A 125(5), 67-73.

Hsuch, C.-H. (1990b). "Interfacial debonding and fiber pullout stresses of fiber reinforced composites." Mat. Sci. and Engrg., Vol. A123, 111.

Hsueh. C.-H. (1991a). "Interfacial debonding and fiber pullout stresses of fiber reinforced composites, III: with residual radial and axial stresses." Mat. Sci. and Engrg., Vol. A145, 135-142.

Hsueh, C.-H. (1991b). "Interfacial debonding and fiber pullout stresses of fiber reinforced composites. IV: sliding due to residual stresses." Mat. Sci. and Engrg., Vol. A 145, 143-150.

Hutchinson. J. W.. and Jensen, H. M. (1990). "Models of fiber debonding and pullout in brittle composites with friction." Mech. of Mat., Vol. 9.139-163

Lahnert, B. J., Houde, J., and Gerstle, K. H. (1984). "Direct measurement of slip between steel and concrete." ACI J., 83(86). 974982.

Lawrence. P. J. (1972). "Some theoretical considerations of fiber pullout from an elastic matrix." J. Mat. Sci. Vol. 7. 1-7.
Naaman, A. E. et al. (1991a). "Fiber pullout and bond slip. I: Analytical study." J. Struct. Engrg. ASCE, 117(9), 2769-2790.

Naaman, A. E. et al. (1991b). "Fiber pullout and bond slip. II: Experimental validation." J. Struct. Engrg., ASCE, 117(9), 2791-2800.

Naaman, A. E., and Najm, H. S. (1991). "Bond-slip mechanism of steel fibers in concrete." ACI Mat. J., 88(2), 135-144.

Nilson, A. H. (1972). "Internal measurement of bond slip." Am. Concrete Inst, J., 69(7), 439-441.

Orangun, C. O., Jirsa, J. O., and Breen, J. E. (1977). "A recvaluation of test data on development length and splices." ACI J. , (Mar.), $114-$ 122.

Outwater, J. P., and Murphy, M. C. (1969). "On the fracture energy of unidirectional laminate." Proc., 24th Annu. Tech. Conf. of Reinforced Plastics/Composite Div. : Paper No. 11c. Soc. of the Plastics Industry, Inc. New York.

Pijaudier-Cabot, G., Mazars, J., and Pulikowski, J. (1991). "Steel-concrete bond analysis with nonlocal continuous damage." J. Struct. Engrg. ASCE, $117(3), 862-882$.

RILEM Committee TC 89-FMT. (1990). "Size effect method for determining fracture energy and process zone of concrete." Mat. and Struct. Paris, France, Vol, 23, 461-465.

Rots, J. G. (1985). "Bond slip simulation using smeared cracks and/or interface element." Res. Rep. 85.01., Dept. of Struct. Mech., Delft Univ. of Technol., Delft, The Netherlands.

Stang. H. and Shah, S. P. (1986). "Failure of fiber-reinforced conposites by pullout fracture." J. Mat. Sci. , Vol. 21, 953-957.

Takaku, A., and Arridge, R. G. C. (1973). "The effect of interfacial radial and shear stress on fiber pullout in composite materials." $J$. of Phys.-D. Vol. 6, 2038-2047.

Yue. C. Y., and Cheung, W. L. (1992a). "Interfacial propertics of fibrous composites: model for the debonding and pullout process." $J$. Mat Sci., Vol. 27. 3173-3180.

Yue, C. Y., and Cheung, W. L. (1992b). "Interfacial properties of fibrous composites. Determination of interfacial shear strength, interfacial coefficient of friction and the shrinkage of the fiber." J. Mat. Sci., Vol. 27, 3181-3191 